\title{
Hacia un periodismo de calidad en Ecuador: perspectivas de periodistas y audiencia
}

\author{
Towards quality journalism in Ecuador: perspectives of \\ journalists and media consumers
}

\section{Para um jornalismo de qualidade no Equador: perspectivas de jornalistas e da audiência}

JAVIER ODRIOZOLA-CHÉNÉ, Universidad de Los Hemisferios, Quito, Ecuador (javiero@uhemisferios.edu.ec) IVÁN RODRIGO-MENDIZÁBAL, Universidad de Los Hemisferios, Quito, Ecuador (ivanr@uhemisferios.edu.ec)

\section{RESUMEN}

Este informe identifica las posturas de los ciudadanos y periodistas ecuatorianos sobre las prácticas profesionales que derivan en periodismo de calidad, ya que en los últimos años el contexto social del país ha afectado la credibilidad de los profesionales y medios. Para profundizar en este alejamiento, se aplicó a los ciudadanos una encuesta que mide la credibilidad de periodistas y medios e identifica los indicadores asociados a un periodismo responsable, y se entrevistó en profundidad a cuarenta periodistas para identificar los condicionantes para el desarrollo de un periodismo de calidad. Así, la diferente concepción que periodistas y audiencia tienen sobre qué lo conforma explica la brecha entre ambos.

Palabras clave: periodismo; audiencias; periodistas; Ecuador; contenidos; credibilidad; calidad.

\section{ABSTRACT}

This report identifies the positions of Ecuadorian citizens and journalists regarding the professional practices that lead to quality journalism, since in recent years the social context of the country has affected the credibility of both professionals and media. To deepen into this estrangement, we conducted a survey that measures the credibility of journalists and media and identifies the indicators associated with responsible journalism; in addition, we conducted in-depth interviews with forty journalists to identify the conditions for the development of quality journalism. Thus, the different conception that journalists and audience have over what composes the latter explains the gap between them

Keywords: journalism; audience; journalist; Ecuador; contents; credibility; quality.

\section{RESUMO}

Este artigo identifica as posições de cidadãos e jornalistas equatorianos sobre práticas profissionais que levam a um jornalismo de qualidade, uma vez que nos últimos anos o contexto social do país afetou a credibilidade dos profissionais e dos meios. Para aprofundar esse tema foi realizada uma pesquisa que mediu a credibilidade dos jornalistas e da mídia e que identificou indicadores associados ao jornalismo com credibilidade, e entrevistou em profundidade quarenta jornalistas para identificar as condições para o desenvolvimento de um jornalismo de qualidade. Assim, a concepção diferente que os jornalistas e a audiência têm sobre o que o faz um jornalismo ser de qualidade explica a diferença entre as percepções desses dois grupos.

Palavras-chave: jornalismo audiências; jornalistas; Equador; conteúdo; credibilidade; qualidade.

Forma de citar:

Odriozola-Chéné, J. \& Rodrigo-Mendizábal, I. (2017). Hacia un periodismo de calidad en Ecuador: perspectivas de periodistas y audiencia. Cuadernos.info, (41), 175-192. https://doi.org/10.7764/cdi.41.1100 


\section{INTRODUCCIÓN}

El impacto de la crítica generada por el gobierno y la sociedad desde el 2007 al campo de los medios de comunicación en Ecuador -validada luego por la Ley Orgánica de Comunicación-es indudable. La relación entre el anterior presidente de la República, Rafael Correa, y los medios de comunicación en sus diez años de gobierno estuvo marcada por una tensión continua. A partir de la aprobación de la Ley Orgánica de Comunicación en junio de 2013, los medios de comunicación son regulados por la Superintendencia de la Información y Comunicación (Supercom). Este organismo, en sus dos primeros años de existencia, fijó "342 sanciones a canales de televisión, estaciones de radio y periódicos del país" (Carvajal, 2016). La aplicación de la ley ha provocado un enfrentamiento entre aquellos que la consideran un avance en el ejercicio efectivo de la libertad de información y de la participación ciudadana y quienes consideran que supone un control excesivo de carácter político a la práctica periodística (Magdaleno-Alegría, 2016).

Este fenómeno puede relacionarse con el cambio de la forma de informar en el ámbito periodístico, ya que la crítica y las regulaciones tuvieron efectos en la credibilidad de los medios y periodistas ecuatorianos y su labor informativa (Rodrigo-Mendizábal, 2014a, p. 60). Sobre los cambios en el panorama de medios en Ecuador hay diferentes informes en los años recientes: Banegas y Rivera (2012) y su perspectiva del funcionamiento de los medios digitales y convencionales; Checa-Godoy (2011) y su análisis de la tensión política y legal en la conformación del sistema de medios; Punín-Larrea (2011) y su texto sobre la crítica del sector gubernamental al de los medios. En el contexto de la cultura de las rutinas periodísticas nos encontramos con el estudio de Oller, Chavero y Pullas (2015); los mismos Oller y Chavero (2015) emitieron un estudio sobre las influencias que determinan el quehacer periodístico en el país.

En este artículo, se aúnan los resultados de dos proyectos de investigación de la Facultad de Comunicación de la Universidad de Los Hemisferios (Ecuador) relacionados con el panorama de medios y las prácticas periodísticas, considerando, además lo señalado anteriormente.

El primero de los proyectos, Credibilidad de medios, periodistas y fuentes en el Ecuador, se inició en 2009. La investigación longitudinal ha entregado, hasta ahora, índices de credibilidad de la población ecuatoriana sobre medios y periodistas, para dar a la comunidad de investigadores y a quienes forman parte de los medios de comunicación masiva un sistema de datos que les permita mejorar la calidad de la información. Es así que se puede citar a Vásconez-Dávalos (2010) y su visión sobre el periodismo de calidad en Ecuador; RodrigoMendizábal (2010) y el análisis sobre la calidad de la información sobre la crisis económica y financiera mundial y la opinión periodística editorial, así como su informe sobre la calidad informativa y la credibilidad de medios y periodistas en el Ecuador (2012). Existe también un análisis del discurso de los editoriales en los diarios ecuatorianos, escrito por Dávila-Zabala (2012); otro sobre cambios de los perfiles de periodistas, medios y fuentes, producto de la fluctuación de la credibilidad de medios en Ecuador entre 20092011, de Cárdenas (2014), y uno sobre la calidad del discurso de opinión sobre la crisis económica mundial en cinco diarios ecuatorianos, escrito por GaiborAspiazu (2013). Más recientemente, Rodrigo-Mendizábal (2014a) ha dado a conocer un estudio sobre la presencia de los medios en la actual democracia, reflejando las tendencias de la credibilidad en Ecuador; asimismo, ha creado un informe sobre la credibilidad de medios y periodistas en Ecuador en 2013 y su relación con lo político (2014b).

El segundo proyecto es el Estudio sobre rutinas periodísticas. Este, de carácter transnacional, detectay compara las condicionantes que afectan la labor de los periodistas de Chile, Argentina, Ecuador, Colombia y México. Es una iniciativa de la Universidad Católica de la Santísima Concepción (Chile) con Fernando GutiérrezAtala, como investigador principal. El proyecto se inició en el año 2014; en él se analiza y fija la importancia de los diferentes condicionantes que determinan el trabajo periodístico, haciendo que se configuren las rutinas y la calidad de las informaciones periodísticas (Gutiérrez et al., 2015; Gutiérrez-Atala, Domínguez-Panamá, Odriozola-Chené, \& Ferreira-Jiménez, 2017; GutiérrezAtala, Ferreira-Jiménez, \&Pajoni, 2015; Gutiérrez-Atala, Odriozola-Chéné, Ferreira, Anaya-Ávila, \& Pajoni, 2016; Gutiérrez-Atala, Odriozola-Chéné \& DomínguezPanamá, 2017; Odriozola-Chéné, Aguirre-Mayorga \& Roa-Chejín, 2016; Odriozola-Chéné, Bernal-Suárez, \& Aguirre-Mayorga, 2016).

El marco anterior marco sirve de referencia para este artículo, que busca comparar la percepción de los sectores de la sociedad que, en el sentido general, conforman la opinión pública ecuatoriana, con la opinión de los periodistas nacionales sobre los condicionantes que determinan su labor profesional. El objetivo es identificar las posturas similares o diferentes de la audiencia 
y los periodistas respecto de una praxis profesional que derive en un periodismo de calidad, lo que permite explicar la ruptura de confianza de la audiencia en el trabajo periodístico. Las diferentes posturas ponen en relieve el debate tradicional sobre la función de los medios como difusores "de los discursos de la ideología dominante (...) [o como] un lugar donde confluyen intereses diversos" (Igartua \& Humanes, 2004, p. 31).

La hipótesis central sostiene que la credibilidad otorgada por los ciudadanos a los medios y periodistas ecuatorianos se ve afectada por las diferentes maneras de entender la comunicación periodística y el proceso informativo por parte de las audiencias y los periodistas.

\section{MARCO TEÓRICO}

LA CREDIBILIDAD DE LA INFORMACIÓN POR PARTE DE LAS AUDIENCIAS

Se considera la credibilidad como "el efecto que tiene la información en las personas” (Rodrigo-Mendizábal, 2012, p. 55); esta está determinada por las inferencias y decisiones que los lectores realizan basándose en la información publicada. Por otro lado, la credibilidad también se relaciona con cómo se presenta la información, a sabiendas de que esta, si bien se considera objetiva, tiene una orientación, sesgos, un encuadre que puede implicar énfasis o exclusiones de datos, haciendo que la realidad aparezca de una determinada manera.

Se deduce que la información publicada es una, y la recepción que de ella se hace, es otra. Barrios-Rubio, retomando a Miquel Rodrigo Alsina, señala que si bien existen tres factores en el acto de la comunicación, a saber, "la emisión, la construcción y circulación de sentidos (mensaje) y la recepción, [esta última supondría un] acto consciente, activo, [que] no se refiere solo al momento de exposición del sujeto al medio de comunicación, en particular al artefacto, sino que se realiza cuando este usa en su cotidianidad la información recibida, la apropia, la resignifica, crea nuevos sentidos y la hace recircular al convertirla en su propio discurso" (Barrios-Rubio, 2009, pp. 269-270). En tal sentido, la forma en que se construye la noticia, su contexto de circulación y su recepción es un acto reflexivo por el cual el lector también puede hacer cursos de acción.

Hoy en día, los medios de comunicación en Ecuador están -para usar una expresión popularizada en ciertos sectores críticos-, "en la mira"; es decir, se inscriben en un contexto del cual no pueden eludirse, más aún cuando el objeto de sus publicaciones es la realidad social, pública, política del país y del mundo. No se puede decir que los medios estén al margen de dicho contexto, más incluso cuando a este se le puede ver como un campo de discursividades contrapuestas -respecto de la noción de campo, seguimos el debate propuesto por Bourdieu (2008)-: las de gobierno, las de sectores sociales, las de medios, las de diversos actores en las redes sociales, etc. En dicho campo, prevalece una diversidad de voces que pugnan por la puesta en circulación de sentidos o de significados. Entonces, la recepción y la credibilidad se ve influida por tales tensiones y por las determinaciones legales que, por otro lado, ponen en conflicto lo que se considera como libertad de expresión (Cerbino \& Ramos, 2009; Punín-Larrea, 2011), y ponen de manifiesto hasta qué punto hay prácticas responsables a nivel periodístico (Abad-Ordóñez, 2012, p. 5).

\section{INFLUENCIAS EN EL DESARROLLO DE LA PROFESIÓN PERIODÍSTICA}

A la hora de estudiar los condicionantes que influencian el desarrollo de la profesión periodística, Shoemaker y Reese (2014) identifican cinco capas de influencia: (a) la propia psicología del periodista; (b) las rutinas periodísticas; (c) las pautas organizacionales de los medios; (d) las fuentes externas, y (e) la ideología social predominante. Estas influencias no se desarrollan de manera horizontal, sino que se establecen siguiendo una jerarquía de influencias "que propone importantes distinciones entre los niveles de análisis y sitúa al periodista individual en una red de limitaciones organizacionales e ideológicas" (Reese, 1999, p. 48). En este sistema, "esas fuerzas actúan simultáneamente en diferentes niveles (...) Y aun cuando resulta tentador situar la explicación en una única causa, la realidad enseña que, en una red de fuerzas interconectadas, nuestras opciones de análisis son una cuestión de énfasis" (Reese, 1999, p. 57). Por tanto, los condicionantes ideológicos de los periodistas se ven limitados por una serie de condicionantes organizacionales, relacionados con la organización jerárquica de los medios y las propias rutinas periodísticas, que a su vez dependen del propio contexto social en el que los profesionales de la información y los medios se desenvuelven. En definitiva, la influencia contextual del trabajo periodístico puede estudiarse desde tres niveles: sistemas, institución y actor (Oller, 2012, p. 54).

Po su parte, al analizar la influencia de los diferentes condicionantes en los periodistas ecuatorianos, hay que destacar la investigación realizada por Oller y Chavero 
(2015). En su estudio, por medio de 31 entrevistas en profundidad a periodistas ecuatorianos en activo, detectaron que: (a) las principales influencias internas son las nuevas tecnologías, las convicciones éticas, los superiores y los plazos de las noticias, y (b) las principales influencias externas se refieren a la legislación de los medios, la audiencia, las fuentes informativas y el Gobierno y las organizaciones encargadas de controlar y regular los medios (Oller \& Chavero, 2015, p. 95).

\section{EL CONCEPTO DE CALIDAD PERIODÍSTICA}

El otro tema que subyace a la cuestión de la credibilidad de medios y periodistas es la calidad de la información. Y no solo es en cuanto a su percepción, sino también en cuanto a su producción.

Al abordar la calidad periodística, nos encontramos con múltiples factores que marcan el trabajo periodístico: ética, rigor informativo, multiplicidad de fuentes, criterio profesional, investigación periodística, capacitación, responsabilidad, pluralismo, instrumentos deontológicos, aportes al sistema democrático, entre sus aspectos más relevantes (Foro de Periodismo Argentino, 2008, p. 5). Tal y como constata McQuail (1992), los estándares utilizados para medir la calidad periodística son muy diversos.

De manera general, puede afirmarse que son tres las acepciones que han alcanzado una mayor relevancia a la hora de investigar sobre el periodismo de calidad: calidad periodística -journalistic quality-, calidad de las noticias - news quality - y calidad de los contenidos de las noticias -news content quality- (Ramírez de la Piscina, González, Aiestarán, Zabalondo \& Aguirre, 2014, p. 250). Esta heterogeneidad se traslada también a la propia configuración de las investigaciones centradas en el análisis del periodismo de calidad. Así, nos encontramos con que los factores que determinan la calidad periodística varían en nombre y número en las diferentes investigaciones realizadas (Bogart, 1989; De Pablos-Coello \& Mateos-Martín, 2004; GómezMompart \& Palau-Sampio, 2013; McInerney \& Bird, 2005; Pellegrini, Puente, Porath, Mujica, \& Grassau, 2011; Red de Periodismo de Calidad, 2006; Shapiro, 2010; Teramo, 2006; Wimmer \& Dominick, 1996).

En relación con la calidad periodística, Shapiro establece cinco principios básicos que ayudan a un mejor desempeño de la profesión: (a) descubrimiento -búsqueda de la información-; (b) examen -someter esa información a escrutinio-; (c) interpretación - descifrar la historia que cuentan los hechos-; (d) estilo -uso de un lenguaje moldeado para la historia-, y (e) presentación -enganchar a la comunidad con la historia construida-(Shapiro, 2010, p. 104).

Al analizar el proceso informativo, Pellegrini, Puente, Porath, Mujica y Grassau (2011) diferencian entre la selección del acontecimiento que se convertirá en relato periodístico y la elaboración del producto en sí (p. 26). En lo referente al proceso de selección, que encajaría con el concepto de news quality, la calidad se determina por medio de indicadores como el tipo de noticia, el origen de la información, el tema, las fuentes consultadas o la magnitud del acontecimiento (Pellegrini et al., 2011, p. 31). Por su parte, Teramo (2006) se refiere a un conjunto de indicadores para señalar la calidad de los mensajes en el contexto de la comunicación informativa: confiabilidad -ligado al pluralismo del medio-, relevancia -o importancia de un tema-, interés -en relación a las necesidades de los lectores-, proporción -espacio o tiempo de dedicación a un tema-, adecuación-o contexto-, transparencia-o tipo de encuadre-, precisión -corrección lingüística-, claridad -comprensibilidad-, integración-correlación de contenidos con otros recursos como imágenes, etc.-, incidencia correspondencia con el público lector-(p. 76). Muchos de estos están intrínsecamente entrelazados; evidenciándose en el producto periodístico final y, como tal, en la reconstrucciónde la realidad que transmite dicha información. De ahí que, en términos de la credibilidad, la calidad, es decir, los aspectos fundamentales que hacen que la información sea considerada como relevante, veraz, objetiva, transparente, etc., llevan a que las personas se elaboren imágenes respecto de los hechos y situaciones, además que sirven para que los lectores valoren no solo la realidad objetivada sino también el propio material publicado, considerándolo de preeminencia para el curso de su vida cotidiana. En cierto sentido, es posible que la transgresión a ciertos indicadores de calidad se constituya en el argumento central de la crítica sectorial que se ha desatado en los últimos tiempos al campo de los medios de comunicación en Ecuador. La consecuencia de ello, es que "las audiencias [no] estén debidamente informadas y puedan ejercer su derecho ciudadano a la participación y la toma de decisiones en asuntos de interés público" (Villamarín-Carrascal, 2013, p. 24).

Por último, en cuanto a los indicadores observables respecto de la calidad de contenido de las noticias, la variedad temática y la profundidad de la agenda ha sido utilizada como instrumento de medida de la calidad en los contenidos periodísticos (Bogart, 1989), en contraposición a la homogeneización de contenidos 
que adolece la práctica periodística en la actualidad (Boczkowski \& de Santos, 2007; Odriozola-Chéné \& Llorca-Abad, 2014). Otros indicadores de la calidad de los contenidos de las noticias serían: la capacidad de generar relatos propios sin la dependencia de la información de agencias (Lacy \& Fico, 1991); la diversidad en el uso de géneros que posibilita diferentes acercamientos a un mismo acontecimiento (MartínezAlbertos, 2004); la variedad en el uso de fuentes informativas que evita que determinados sujetos se configuren como los actores legitimados en la reconstrucción de la realidad social (Casero-Ripollés, 2008, p. 120) y el estilo, contenido y énfasis de los productos periodísticos en su proceso creativo (Alessandri et al., 2001, p. 118).

\section{METODOLOGÍA}

Lo expuesto en el este artículo parte de un enfoque mixto de investigación, para comprender la credibilidad y calidad periodística desde la visión tanto de las audiencias como de los periodistas ecuatorianos.

Para la obtención de los indicadores de credibilidad de la población ecuatoriana en los medios y los periodistas entre 2009 y 2014, se realizó una encuesta nacional anual en las ciudades de Quito, Guayaquil y Cuenca, considerándolas como las ciudades más importantes de Ecuador ya que están en el eje económico y productivo. La pertinencia de dichas ciudades en la encuesta también radica en el hecho de que congregan a los flujos de movimiento poblacional actual de otras ciudades del país. El periodo de realización de la toma de datos mediante la encuesta fue preferentemente entre los meses de mayo-abril. La encuesta se operativizó con un cuestionario estructurado de 20 preguntas de selección múltiple, que hasta la actualidad permite la obtención de varios índices. Lo expuesto en este artículo es un rango de datos. Para la selección de la muestra se utilizó la siguiente fórmula: $\mathrm{n}=0,25^{*} \mathrm{~N} /(\mathrm{a} / \mathrm{z}) 2(\mathrm{~N}-1)+0,25$. Los valores aplicados son los siguientes: $\mathrm{n}=$ tamaño población; a=5\%; z=1,959; N=95\%. De acuerdo a la fórmula, la población encuestada por cada ciudad fue de 384, siendo el total de 1152 individuos de entre 18 y 55 años. El rango de encuestados fue entre profesionales, no profesionales y estudiantes universitarios. Una vez recogidos los datos en cada una de las ciudades, se verificaron tomando en cuenta muestras al azar, haciendo llamadas telefónicas a algunos individuos de la muestra. Luego se depuraron los datos usando Excel; una vez consolidados aquellos, se empleó SPSS.

Por otra parte, para determinar los condicionantes considerados por los periodistas como los más relevantes para el desarrollo de una práctica periodística de calidad, se realizaron entrevistas en profundidad, definidas "como un cuestionario con menor estructuración que combina preguntas con las alternativas de respuesta predefinidas junto a otras abiertas en las que el entrevistado contesta con total libertad" (Vieytes, 2004, p. 322). En primer lugar, se preguntó a los periodistas de manera abierta cuáles consideraban que eran los principales condicionantes para el desarrollo de un periodismo de calidad. Las respuestas fueron ubicadas en uno de los diez condicionantes de medición: ideológicos, políticos, jerárquicos, económicos, laborales y salariales, formativos, tecnológicos, presión social, rutinas periodísticas y condiciones de trabajo (Odriozola-Chené, Gutiérrez-Atala, Ferreira-Jiménez, \& DomínguezPanamá, 2017, pp. 160-161). En una segunda parte se preguntó al entrevistado si identificaba en su desempeño profesional alguna de las categorías establecidas como condicionantes. La muestra fue de 40 profesionales de la información que trabajan en medios de comunicación de Quito en diferentes soportes: Internet, prensa, radio y televisión (tabla 1). Las entrevistas se desarrollaron entre octubre de 2014 y febrero de 2015. Dado su carácter anónimo y debido a que está investigación se enmarca en un proyecto internacional, el rango otorgado a los periodistas ecuatorianos entrevistados abarca desde el Sujeto 121 hasta el Sujeto 160.

\section{RESULTADOS}

La credibilidad de medios y periodistas en Ecuador Los datos sobre la credibilidad de los medios ecuatorianos (gráfico 1) reflejan que la televisión y la prensa se configuran como los soportes más creíbles para las audiencias, mientras que la credibilidad de los medios radiofónicos se ha ido asentando en los últimos años. Por su parte, los cibermedios muestran un índice inferior al de los medios tradicionales, pero en constante crecimiento.

La credibilidad de los periodistas ecuatorianos (gráfico 1) es inferior que la de sus propios medios; se observa una tendencia decreciente en la credibilidad de los periodistas de los soportes tradicionales, y una ascendente en la de los ciberperiodistas, aunque aún inferior a la de los periodistas de televisión y radio.

\section{Factores de credibilidad y condicionantes del trabajo periodístico}

El gráfico 2 refleja los factores problemáticos que afectan a la credibilidad. Los dos valores que más destacan a lo largo de la encuesta longitudinal son 
VARIABLES SOCIODEMOGRÁFICAS

\begin{tabular}{|c|c|}
\hline \multicolumn{2}{|l|}{ Sexo } \\
\hline Masculino & $67,5 \%[27]$ \\
\hline Femenino & $32,5 \%$ (13) \\
\hline \multicolumn{2}{|l|}{ Edad } \\
\hline Media & 37,5 \\
\hline \multicolumn{2}{|l|}{ Nacionalidad } \\
\hline Ecuatoriana & $97,5 \%[39]$ \\
\hline Española & $2,5 \%[1]$ \\
\hline \multicolumn{2}{|l|}{ VARIABLES LABORALES } \\
\hline \multicolumn{2}{|l|}{ Soporte mediático* } \\
\hline Cibermedio & $30 \%(12)$ \\
\hline Prensa & $30 \%[12]$ \\
\hline Televisión & $30 \%(12)$ \\
\hline Radio & $32,5 \%[13]$ \\
\hline \multicolumn{2}{|l|}{ Rol organizacional } \\
\hline Redactor/a & $45 \%[18]$ \\
\hline Jefe de sección & $25 \%(10)$ \\
\hline Cargo directivo /Propietario & $30 \%[12]$ \\
\hline \multicolumn{2}{|l|}{ Dedicación exclusiva } \\
\hline Sí & $82,5 \%$ (33) \\
\hline No & $17,5 \%[7]$ \\
\hline \multicolumn{2}{|l|}{ Tipo de contrato } \\
\hline Tiempo completo & $82,5 \%[33]$ \\
\hline Tiempo parcial & $7,5 \%[3]$ \\
\hline Propietario & $2,5 \%(1)$ \\
\hline N.C. & $7,5 \%(3)$ \\
\hline \multicolumn{2}{|l|}{ VARIABLES FORMATIVAS } \\
\hline \multicolumn{2}{|l|}{ Licenciatura en Comunicación } \\
\hline Sí & $80 \%[32]$ \\
\hline No & $20 \%(8)$ \\
\hline \multicolumn{2}{|l|}{ Otra licenciatura } \\
\hline Sí & $35 \%(14)$ \\
\hline No & $65 \%[26]$ \\
\hline \multicolumn{2}{|c|}{ Título de cuarto nivel en Comunicación } \\
\hline Sí & $35 \%(14)$ \\
\hline No & $65 \%(26)$ \\
\hline \multicolumn{2}{|c|}{ Título de cuarto nivel en otras áreas } \\
\hline Sí & $7,5 \%(3)$ \\
\hline No & $92,5 \%$ [37] \\
\hline \multicolumn{2}{|l|}{ Formación continua } \\
\hline Sí & $57,5 \%[23]$ \\
\hline No & $42,5 \%[17]$ \\
\hline
\end{tabular}

Tabla 1. Características sociodemográficas, laborales y formativas de los periodistas entrevistados

* El porcentaje total de la variable "Soporte mediático" es mayor al 100\%, puesto que los periodistas, en ocasiones, trabajan en diferentes medios $y$ soportes.

Fuente: Elaboración propia. 

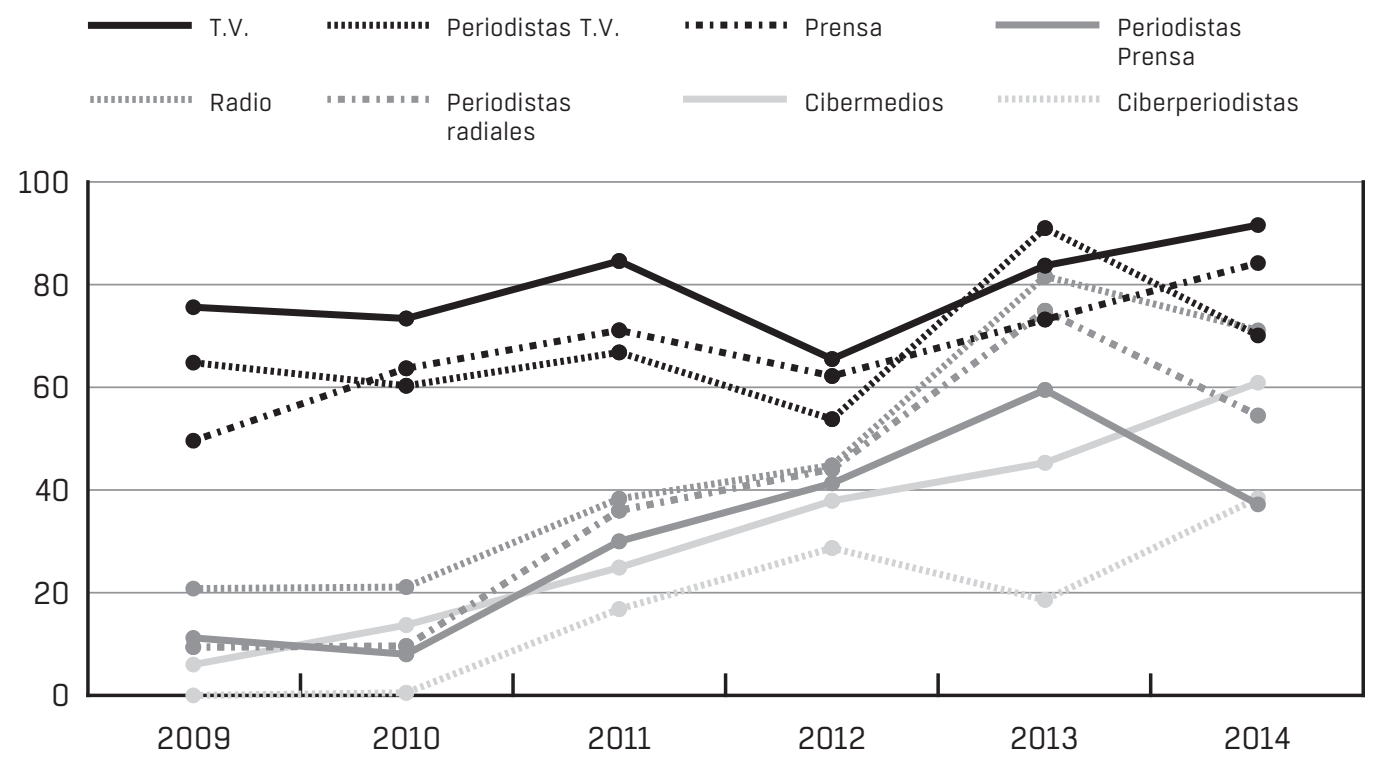

Gráfico 1. Credibilidad de medios y periodistas [2009-2014] [\%]

Fuente: Elaboración propia.
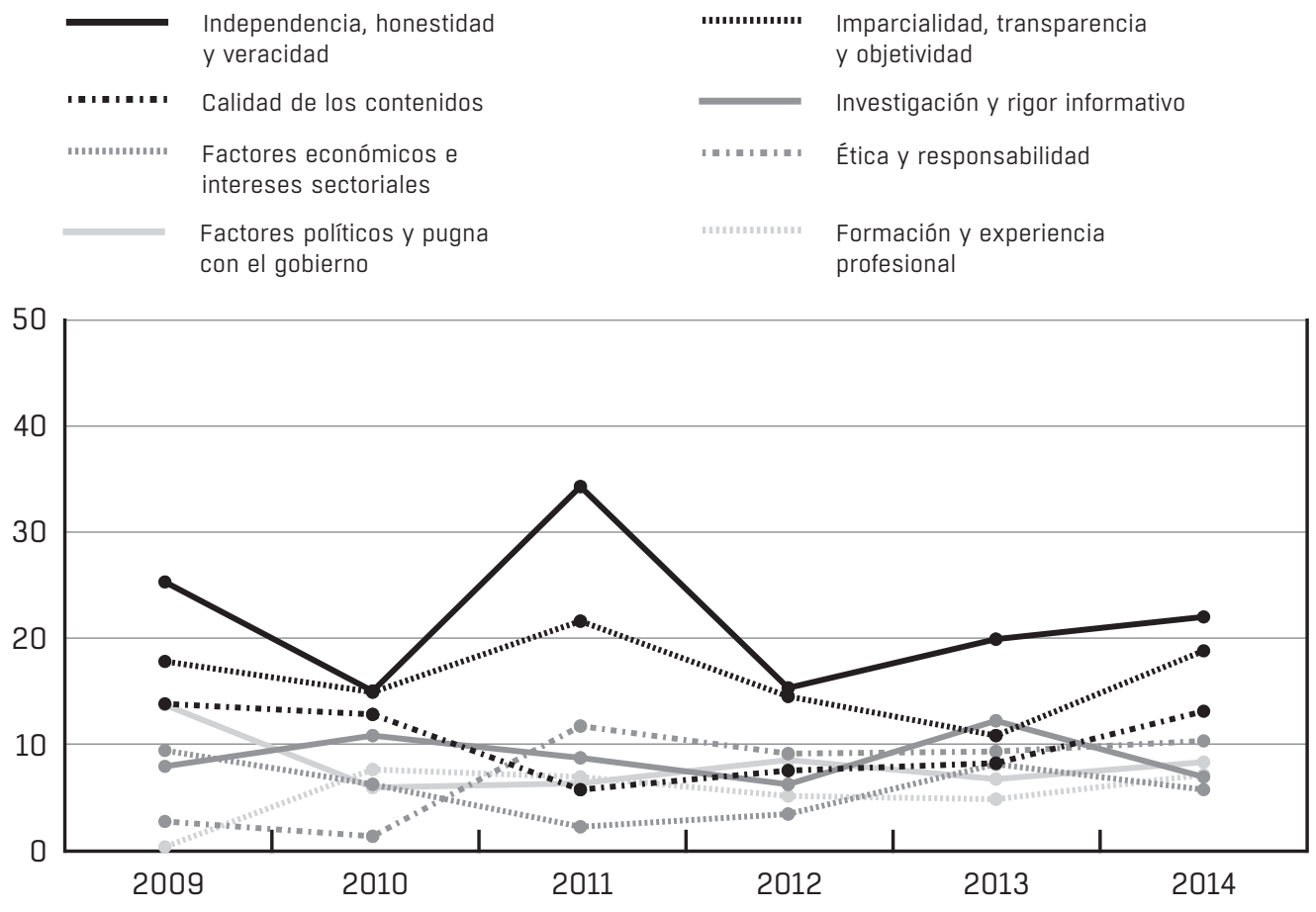

Grafico 2. Factores que afectan a la credibilidad de medios y periodistas (2009-2014) (\%) 
Condicionantes

Presencia $(n=40)$

\begin{tabular}{lc}
\hline Políticos & $65 \%$ \\
\hline Rutinas periodísticas & $37,5 \%$ \\
\hline Condiciones de trabajo & $30 \%$ \\
\hline Económicos & $20 \%$ \\
\hline Formativos & $17,5 \%$ \\
\hline Jerárquicos & $12,5 \%$ \\
\hline Salariales/laborales & $12,5 \%$ \\
\hline Tecnológicos & $12,5 \%$ \\
\hline Presión social & $12,5 \%$ \\
\hline Ideológicos & $10 \%$ \\
\hline
\end{tabular}

Tabla 2. Condicionantes que afectan al desarrollo de un periodismo de calidad

Fuente: Elaboración propia

independencia, honestidad y veracidad, e imparcialidad, transparencia y objetividad. Si bien estos se asocian a las características individuales del periodista, se ven condicionados tanto por las presiones externas al medio como por las jerárquicas de la institución mediática. En esta línea también se podría enmarcar la categoría sobre ética y responsabilidad. Otros factores se asocian con las propias rutinas periodísticas -investigación y rigor informativo o calidad de los contenidos-; la formación recibida-formación y experiencia profesional-, o directamente con las presiones externas de agentes políticos y económicos -factores económicos e intereses sectoriales o factores políticos y pugna con el gobierno-

Al relacionar los datos con las respuestas de los periodistas ecuatorianos (tabla 2), se observa que, dentro de los diferentes factores que afectan al desarrollo óptimo de su profesión, los periodistas consideran que los condicionantes más importantes son: (a) las presiones políticas (65\%); (b) las rutinas periodísticas (37,5\%), y (c) las condiciones de trabajo, vinculadas tanto a la disposición de los recursos necesarios como a las condiciones de clima laboral y relaciones interpersonales (30\%). Cabe destacar que los condicionantes derivados de las presiones jerárquicas de los medios $(12,5 \%$ ) y de la propia ideología del periodista (10\%) son de escasa importancia para los profesionales entrevistados. Por encima de ellos, se sitúan otras cuestiones como la formación recibida (17,5\%) o la situación económica de Ecuador (20\%).

Por lo tanto, los factores que más contribuyen a afianzar la credibilidad (independencia, honestidad y veracidad, e imparcialidad, transparencia y objetividad) se derivan de la propia figura del periodista y del medio. Sin embargo, los profesionales no perciben como importantes los condicionantes que emanan de su propia figura y del medio en el que trabajan. De esta manera, se observa una primera brecha entre la percepción de los periodistas y la de la ciudadanía/audiencia.

Además, los ciudadanos también consideran importantes la investigación y rigor informativo y la calidad de los contenidos a la hora de determinar la credibilidad de los periodistas y los medios de comunicación. Desde la profesión periodística, también se asocia directamente el desarrollo de un periodismo de calidad con las rutinas periodísticas, es decir, hay acuerdo entre ambas visiones.

\section{SECTORES QUE INFLUENCIAN EL TRABAJO PERIODÍSTICO \\ Influencias gubernamentales y políticas}

Tomando los datos del gráfico 2, se podría asegurar que, para la ciudadanía, el índice de factores políticos y pugna con el gobierno como problema que afecta a la credibilidad de medios y periodistas no es tan alto. Sin embargo, en el gráfico 3, los ciudadanos entrevistados evidencian la existencia de presiones políticas.

Para la opinión pública ecuatoriana, las presiones gubernamentales están presentes regularmente (18,8\%), casi siempre (31,7\%) o siempre (25,9\%). Pero, aparte del sector de gobierno, están los partidos políticos, que también ejercen una influencia en los medios y periodistas, aunque en menor medida: regularmente (26,5\%), casi siempre $(26,7 \%)$ o siempre $(19,5 \%)$. 


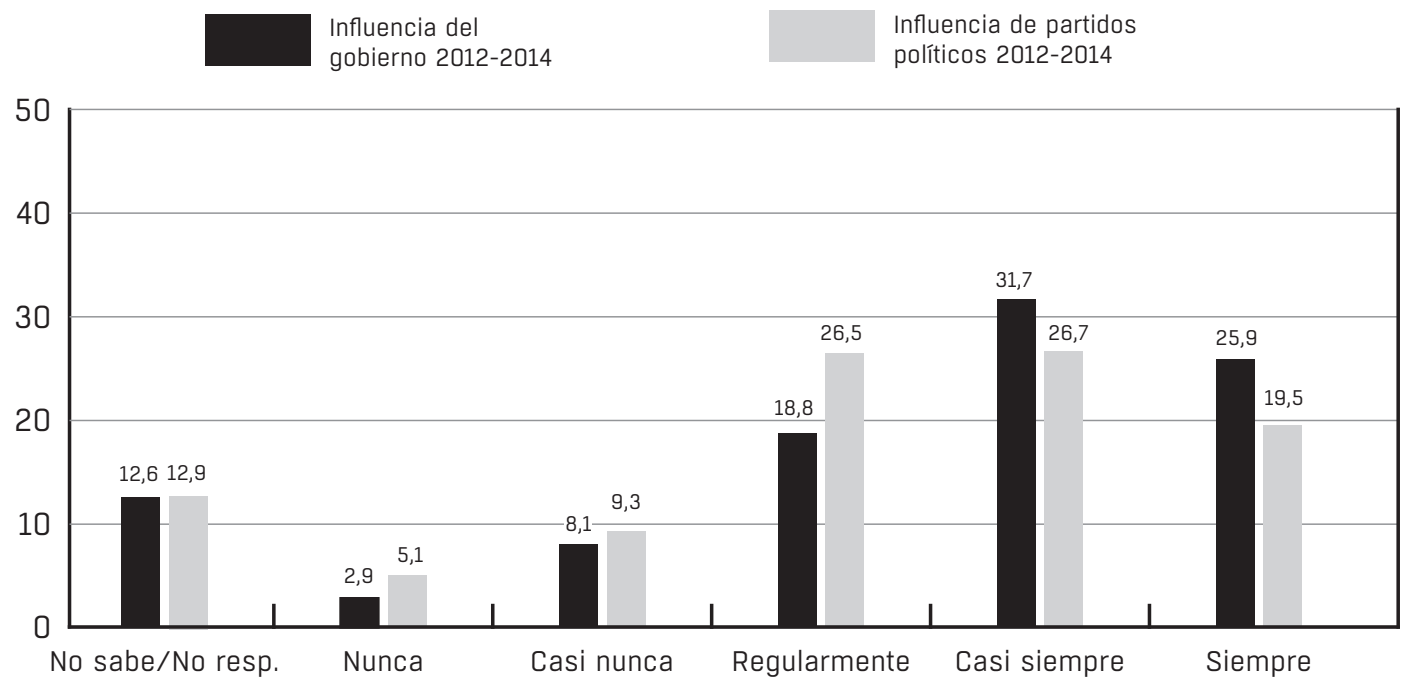

Gráfico 3. Percepción sobre las influencias políticas por parte de los ciudadanos (2012-2014] [\%]

Fuente: Elaboración propia.

Las presiones políticas son percibidas, por parte de los periodistas, como el principal condicionante en el desarrollo profesional (65\%). Al analizar sus respuestas sobre los condicionantes políticos, destacan tres aspectos destacan: (a) las presiones políticas, (b) el nuevo entorno jurídico que surge con la aprobación de la Ley Orgánica de Comunicación, y (c) los problemas de acceso a las fuentes gubernamentales.

En este contexto, los entrevistados reflejan el "temor a ser perseguido, enjuiciado y sancionado" (Sujeto 139), creando "una institucionalidad restrictiva, sancionadora y enajenante que busca poner a los funcionarios por encima del trabajo de los periodistas" (Sujeto 138). Estas presiones se traducen en "campañas enteras para desprestigiar a periodistas que hacen bien su trabajo (...), existe un monitoreo continuo de todos los medios de comunicación o por lo menos de un altísimo porcentaje" (Sujeto 141) y en "sistemáticas estrategias políticas de comunicación y marketing, con el objeto de afectar la noble misión de informar y entretener" (Sujeto 150).

Uno de los aspectos más mencionados por los periodistas dentro de las presiones políticas es la Ley Orgánica de Comunicación, vigente en Ecuador desde el 24 de junio de 2013. Se constata que puede darse un efecto "por el desconocimiento de las leyes que atemoriza a los periodistas" (Sujeto 136) y se afirma que la "ley termina siendo una ley subjetiva en muchos aspectos o de enfoque subjetivo, que determina sanciones y limitaciones para el ejercicio periodístico" (Sujeto 154). Sin embargo, los periodistas entrevistados también consideran que tiene efectos positivos al potenciar "ser mucho más responsables en la información que se entrega" (Sujeto 143) y realizar un mayor esfuerzo periodístico.

Por último, los periodistas ecuatorianos destacan las dificultades de acceso a las fuentes institucionales. Estos problemas se derivan de una problemática mundial puesto que "existen fuerzas políticas, existe una manipulación de la información en general, en el mundo entero" (Sujeto 158). En Ecuador, "es muy complicado tener la fuente oficial" (Sujeto 159). Así, "se trata más de un tema de censura previa, o sea, estamos claros en que el Gobierno no habla, no da entrevistas, entonces se vuelve complicado hacer temas que necesariamente requieren contrastación" (Sujeto 129).

La presión de las instituciones políticas sobre los medios de comunicación y los periodistas es reconocida tanto por la ciudadanía/audiencia como por los propios periodistas. Se muestra, por tanto, una percepción similar desde ambas posiciones.

Otras influencias: sectores empresariales, sindicatos, organizaciones civiles y ciudadanía

La influencia de otros sectores no muestra una dinámica constante. Para los ciudadanos, las presiones desde 


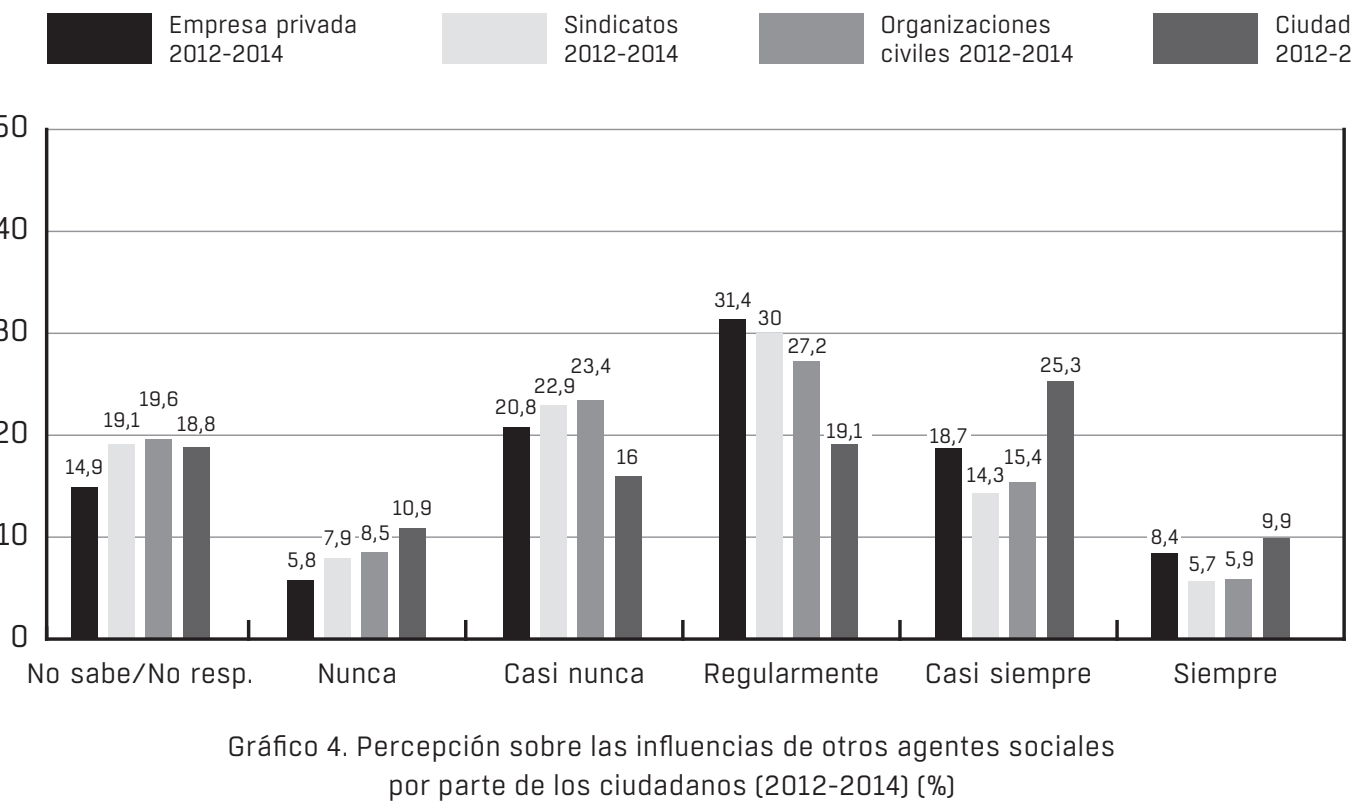

Fuente: Elaboración propia.

la empresa privada existen de manera regular (31,4\%); sin embargo, su presencia no es tan importante ni continua como en el caso de las presiones políticas: casi siempre (18,7\%) y siempre (8,4\%). En el caso de los sindicatos y organizaciones civiles ocurre algo similar. Los ciudadanos consideran que la influencia es regular-sindicatos (30\%) y organizaciones civiles $(27,2 \%)$-, pero su importancia decrece considerablemente respecto de la influencia política y empresarial -en los valores casi siempre, sindicatos $(14,3 \%)$ y organizaciones civiles (15,4\%), y siempre, sindicatos (5,7\%) y organizaciones civiles (5,9\%)-.Por último, la ciudadanía muestra una consciencia en su capacidad de influir en los medios de comunicación similar a la de la empresa privada, sindicatos y organizaciones civiles, pero con un reparto diferente dentro de los valores: regularmente (19,1\%), casi siempre (25,3\%) y siempre (9,9\%).

La presión social, entendida como la presión que la sociedad (mediante sus diversos grupos) ejerce en el periodista y en el medio, para la instalación de sus demandas en el escenario informativo, es considerada como un condicionante fundamental por el $12,5 \%$ de los periodistas entrevistados.

Sin embargo, al profundizar en los condicionantes en la segunda parte de la entrevista semi-estructurada, se observa que, desde la profesión periodística ecuatoriana, se perciben intentos de presión desde "todos lados, pero nunca influyen en tu trabajo" (Sujeto 128), tanto "las organizaciones públicas y privadas tratan de darte el enfoque" (Sujeto 125). Así, "si hay un grupo o un sector que está con criterios en contra o protagonizando alguna medida de hecho, lo que hacemos es que tomamos su versión e inmediatamente vamos a contrastarla" (Sujeto 152).

En cuanto a la presión ejercida por la propia ciudadanía/audiencia, los periodistas consideran que, pese a que su trabajo sufra presiones desde diferentes ámbitos, "la presión más fuerte es la de la opinión pública. La gente nos exige que se publique la información" (Sujeto 137). Derivado de este punto se reflejan diferentes perspectivas de cómo deben actuar los periodistas para cumplir esta función social. La primera construye sus relatos periodísticos teniendo en cuenta que se "trabaja para el público y sus intereses, nuestra obligación es interpretar esos intereses, saber qué es lo que la gente quiere saber, para satisfacer esa necesidad" (Sujeto 154). Desde esta perspectiva, el no tener en cuenta los intereses de la audiencia puede provocar "un proceso paulatino de 'desclasamiento' que les aleja de la sociedad en su conjunto y tratan de ubicarse en una escala en la que están las autoridades públicas, los actores sociales reconocidos..." (Sujeto 153). Desde la perspectiva contraria se afirma que "hay temas que la gente debe saber, aunque no los quiera" (Sujeto 134). De esta manera, el periodista debe ejercer de filtro intelectual, puesto que "no te puedes dejar llevar por 


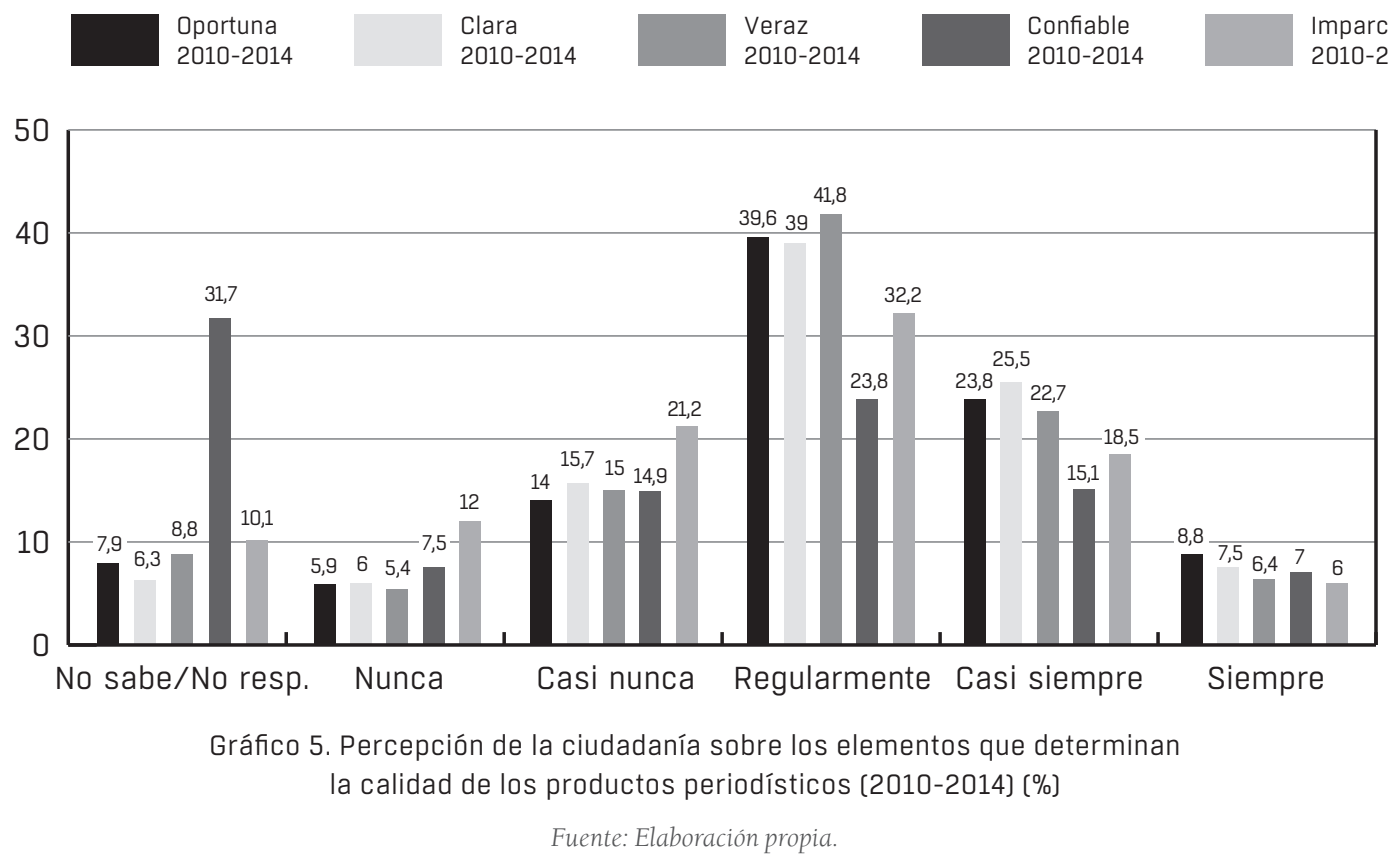

la presión, porque a veces la presión social puede dibujarse como un error y tú cometes el error (...) A veces tienes presión de por qué no dices esto, por qué no informas esto, deberías denunciar esto... pero no tienes las bases, no tienes los argumentos" (Sujeto 155).

Al comparar la perspectiva de periodistas y ciudadanía, se observa que, pese a la capacidad de influencia que los ciudadanos otorgan a ciertos sectores como la empresa privada, sindicatos u organizaciones sociales, los periodistas no creen que la presión ejercida por ellos influya en el desarrollo de sus productos periodísticos. Aquí se observa de nuevo una diferente concepción entre la visión de la ciudadanía y la de los periodistas. En lo referente a la capacidad de influencia de la propia ciudadanía como audiencia de los medios de comunicación, los ciudadanos encuestados consideran que sí tienen capacidad de influencia. Esta posibilidad de influir en el trabajo periodístico depende de la propia concepción de los periodistas respecto de la importancia de reflejar en sus productos los intereses de la audiencia. Por tanto, en esta ocasión se observa que la visión de la ciudadanía y los periodistas puede converger o divergir, en función de la propia concepción de la profesión por parte de los periodistas.

\section{La calidad periodística vista desde la audiencia y desde la profesión}

En el gráfico 5 se analiza la calidad periodística considerando el lugar de la audiencia y la profesión.

Los ciudadanos ecuatorianos consideran que los elementos que determinan la calidad de los productos periodísticos muestran una presencia desigual en las informaciones de los medios de comunicación ecuatorianos.

En primer lugar, para los encuestados, la información propagada por los medios ecuatorianos suele ser oportuna regularmente $(39,6 \%)$, casi siempre $(23,8 \%)$ y siempre (8,8\%). Este hecho está relacionado con que los periodistas piensan que es necesario "hacer un periodismo un poco más cercano a la gente, pensando que la gente tenga más cercanía con el trabajo que hacemos, darle mayor facilidad de lectura" (Sujeto 122). En estos momentos, los periodistas comienzan a ser conscientes del cambio de paradigma en la comunicación mediática, en la que se refuerza "la necesidad y deseo de interactuar del público” (Sujeto 138).

En segundo lugar, los ciudadanos encuestados consideran que la claridad también está presente en las informaciones regularmente (39\%), casi siempre $(25,5 \%)$ y siempre (7,5\%). Por su parte, los periodistas entrevistados también muestran la relación entre claridad y calidad. La claridad comunicativa se asienta, para algunos periodistas, en las bases obtenidas en su formación académica universitaria, que les dotó de "todo lo que tiene que ver con redacción, gramática, géneros..." (Sujeto 122), provocando que haya "una nueva ola de gente 
que llega de las aulas, con mucha más capacidad para poder emitir comunicación e información" (Sujeto 143). Gran parte de los periodistas encuestados creen que en la universidad se adquieren las bases necesarias para el desempeño de la profesión, aunque hay periodistas que detectan un "desfase, el desencuentro entre el proceso de formación y las actividades que desarrolla un periodista en un medio de comunicación" (Sujeto 148).

La veracidad es la tercera característica, relacionada con la calidad, que habitualmente está presente en los relatos de los medios de comunicación ecuatorianos, según los encuestados, regularmente (41,8\%), casi siempre (22,7\%) y siempre (6,4\%). Para los periodistas, esta veracidad se asienta en que "hay que tener fuentes para publicar informaciones que estén contrastadas" (Sujeto 121). Así, "si no atribuyes las declaraciones significa que empezaste a inventar las cosas. Lo que buscas es acercarte a una verdad, mientras más indagas en los actores, más real será tu visión" (Sujeto 135). Sin embargo, los periodistas también constatan los hándicaps de "la reportería digital contemporánea ya no se hace trabajo de campo, de verificación” (Sujeto 153). La Ley Orgánica de Comunicación se ha convertido en un elemento que aumenta la importancia de la veracidad, puesto que "obliga el tema de tener todas las fuentes posibles" (Sujeto 151).

El desarrollo de la imparcialidad y de la confiabilidad de los medios de comunicación ecuatorianos no muestra unos valores tan altos en las respuestas de los ciudadanos: regularmente (23,8\% la imparcialidad y $32,2 \%$ la confiabilidad), casi siempre (15,1\% la imparcialidad y $18,5 \%$ la confiabilidad) y siempre (7\% la imparcialidad y $6 \%$ la confiabilidad). Estos aspectos deben relacionarse con los propios condicionantes derivados de la opinión personal del periodista y del medio en el que trabaja, tanto ideológicos como jerárquicos. Los periodistas afirman que "hablar de imparcialidad en el periodismo es bastante ingenuo" (Sujeto 123). Los condicionantes ideológicos del propio periodista están presentes en la mayoría de los entrevistados, ya que "el periodista no es una refrigeradora, es un ser humano, que tiene una visión cultural del mundo, de la sociedad y de la política" (Sujeto 146). Los periodistas son conscientes de la influencia de sus puntos de vista al tratar las informaciones, aunque procuran limitarlos por medio de la ética y el ejercicio responsable de la profesión. Cuando estos principios no se cumplen, la profesión periodística cae en "la polarización y el simplismo. Mirar los hechos, las historias como buenos o malos, en blanco y negro, a favor o en contra" (Sujeto
138). Al hablar de presiones desde los medios, algunos periodistas consideran que estas no se producen y que "la posición ideológica del medio es un tema más de las universidades" (Sujeto 159) o que trabajan "en medios que no tienen este tipo de condicionamientos ideológicos" (Sujeto 146). El punto de vista contrario considera que esa visión contribuye a sustentar la "pretendida apoliticidad de los medios y el engaño supremo de que es posible un periodismo objetivo" (Sujeto 153). Sin embargo, pese a que los periodistas no otorgan gran relevancia a este tipo de condicionantes, dejan constancia en sus respuestas de la importancia de las jerarquías en los medios: "Todos los medios de comunicación tienen una forma de manejarse jerárquicamente, entonces, los directores son los que al final asignan los temas" (Sujeto 157).

Al comparar la presencia de los valores ligados a la calidad que los ciudadanos consideran presentes en los relatos periodísticos de los medios ecuatorianos con la importancia que les conceden los periodistas, se ven tanto coincidencias como divergencias. Es similar la importancia concedida por los periodistas y por los ciudadanos cuando se habla de información oportuna, clara y veraz. Esto muestra que ciudadanos y periodistas comparten una serie de valores a la hora de determinar qué es importante, que los relatos periodísticos comparten el lenguaje habitual del conjunto de la ciudadanía y que la correcta identificación de las fuentes contribuye a que los ciudadanos consideren que las noticias son representativas de los acontecimientos relatados. Sin embargo, para los ciudadanos, valores como la imparcialidad o la confiabilidad no suelen estar tan presentes en los relatos periodísticos. Este hecho está motivado porque, para los periodistas, estos valores se desvanecen en el conjunto de condicionantes personales, profesionales, jerárquicos y externos.

\section{DISCUSIÓN}

La credibilidad que otorga la ciudadanía a los medios de comunicación y a los periodistas es un elemento que inexorablemente va ligado a la evaluación del desarrollo profesional que de ellos hace la ciudadanía. Pero, más allá de evaluar el proceso productivo-informativo, la medida de este quehacer periodístico queda fijada por el producto final: los relatos periodísticos.

En este punto, la credibilidad concedida por la ciudanía/audiencia a los medios y periodistas ecuatorianos muestra algunos elementos destacables. En primer lugar, que los índices de credibilidad no son bajos y 
parecen haberse asentado en los últimos años. Dentro de los medios, la televisión se configura como el más creíble, seguido de los medios impresos. Al hablar de la construcción de la realidad social ecuatoriana, es evidente que la televisión es el lugar actual donde se emite información con contenidos muchas veces más impactantes y aleccionadores sobre determinada realidad. El efecto que causa la información televisiva es claro, por la hechura de las imágenes que van más allá de la retórica de los medios impresos. En el caso de estos últimos, se constata que el sector ha debido reposicionarse si se considera que fue el más combatido y criticado por la calidad de sus contenidos. Sus índices de credibilidad han ido mejorando paulatinamente, recuperando la buena percepción de los públicos.

A su vez, se observa un crecimiento continuo en la credibilidad de los cibermedios. El hecho de que Internet sea un territorio de información más libre, muestra que en lo relativo a la credibilidad de los medios en Ecuador, los lectores y las audiencias necesitan variedad informativa, diversidad de voces, y contenidos más ricos; los medios tradicionales, no obstante, su reposicionamiento, no necesariamente los entregan a los públicos.

Por último, es destacable que, en todos los soportes, la credibilidad de los medios de comunicación siempre es superior a la de sus propios periodistas, lo que lleva a pensar sobre la concepción que tiene la audiencia sobre la figura del periodista, pues tal y como mostraban Shoemaker y Reese (2014), las opiniones y características personales de los periodistas están siempre supeditadas a una serie de influencias que emanan de la propia profesión, del medio en el que trabajan y de sus relaciones con diferentes agentes sociales.

En cuanto a los factores que determinan la credibilidad de los medios y los periodistas ecuatorianos, los ciudadanos vinculan valores que, a simple vista, parecen emanar de los propios medios y profesionales (independencia, imparcialidad, rigor informativo). Sin embargo, en muchas ocasiones estos valores se ven condicionados por otros factores que se derivan tanto de las presiones externas como desde el propio medio y de la propia práctica profesional, que está siendo modificada y cuestionada debido al vertiginoso aumento de los ritmos de producción desde la llegada de Internet.

En un primer momento, los ciudadanos no parecen otorgar importancia a las presiones o influencias externas que reciben los medios de comunicación. Sin embargo, cuando se les pregunta específicamente sobre estas, reflejan su importancia, situando en un primer nivel la a los sectores políticos, y dando un menor peso a la influencia de otros actores sociales como el mundo empresarial, sindical, las organizaciones civiles o la propia audiencia. Por su parte, para los periodistas, las presiones políticas se configuran como el principal condicionante en el desarrollo de un periodismo de calidad. La presión social que pueden llegar a ejercer otros sectores sociales es mucho menor y pone en relieve cómo gran parte de los periodistas se ve más condicionada por lo que esperan sus audiencias que por las presiones a las que intentan someterles esos otros actores sociales.

Por último, a la hora de examinar los valores ligados a la calidad periodística que están presentes en los productos periodísticos ecuatorianos, los ciudadanos determinan como los más habituales la oportunidad, la claridad y la veracidad. Como se ha dicho, los ciudadanos y periodistas ecuatorianos comparten una serie de valores a la hora de determinar qué es importante, compartir un lenguaje común y dotar de significado a los acontecimientos por medio de datos sustentados en fuentes claramente identificadas. Sin embargo, otros valores como la imparcialidad o la confiabilidad, que ya habían sido subrayados por los ciudadanos como fundamentales a la hora de determinar la credibilidad de medios y periodistas, no están tan presentes en los productos informativos, según los encuestados. Los periodistas rechazan la existencia de estos valores, a los que se podría unir la objetividad, pues son conscientes de que en el desarrollo del proceso informativo entran en juego influencias no solo provenientes de las características personales de los periodistas, sino de otras que emanan tanto de los propios medios como de actores sociales con los que los periodistas y sus organizaciones se deben relacionar en el desarrollo de la profesión periodística.

\section{CONCLUSIÓN}

Retomando el objetivo y la hipótesis planteados al comienzo de esta investigación, se constata que la credibilidad otorgada por los ciudadanos a los medios y periodistas ecuatorianos se ve afectada por las diferentes maneras de entender la comunicación periodística y el proceso informativo por parte de audiencias y periodistas.

Si bien es cierto que se muestra una tendencia de consolidación de la credibilidad de la ciudadanía en los medios y periodistas ecuatorianos, hay una serie de factores relacionados con la forma de comprender las especificidades de la profesión periodística que, en 
ocasiones, provoca un choque entre cómo piensa la audiencia que se debe desarrollar el proceso informativo y cómo consideran los periodistas que deben actuar en un mundo marcado por las influencias de todo tipo.

De esta manera, partiendo de valores comunes como la necesidad de rigor periodístico, ética profesional, veracidad, etc., los ciudadanos consideran necesaria la existencia de otros valores como la imparcialidad o la independencia en la realización de un periodismo de mayor calidad que acreciente la credibilidad del mundo periodístico. Frente a ello, los periodistas no estiman importantes ni posibles estos valores debido a las propias subjetividades que surgen no solo de ellos mismos, sino también de las instituciones en las que trabajan, pese a que en un primer momento no sean conscientes, de las prácticas periodísticas y de los actores sociales, fundamentalmente políticos, con los que se relacionan de manera continua. Cabría preguntarse si este choque que se da a la hora de definir la profesión periodística es uno de los motivantes de que la credibilidad de los periodistas sea inferior, en todos los casos, a la de los medios de comunicación en los que trabajan.

\section{REFERENCIAS}

Abad-Ordóñez, G. R. (2012). La responsabilidad social del periodismo: procesos informativos, debates políticos y ejes de políticas públicas en el contexto de la Ley de Comunicación en el Ecuador [The social responsibility of journalism: informative processes, political debates, axes of public policies in the context of the Communication Law in Ecuador]. Quito: Universidad Andina Simón Bolívar.

Alessandri, F., Edwards, C., Pellegrini, S., Puente, S., Rozas, E., Saavedra, G., \& Porath, W. (2001). VAP: un sistema métrico de la calidad periodística [VAP: a metric system of journalistic quality]. Cuadernos de información, (14), 12-120. Retrieved from https://doi.org/10.7764/cdi.14.187

Banegas, D. \& Rivera Rogel, D. E. (2012). Análisis de la empresa informativa impresa y digital de Ecuador [Analysis of the printed and digital information media of Ecuador]. Razón y palabra, 17(79), 56-22. Retrieved from https://goo.gl/nrWeun

Barrios-Rubio, A. (2009). Los jóvenes y la red; usos y consumos de los nuevos medios en la sociedad de la información y la comunicación [Youth and the Net: Use and Consumption of New Media in the ic society]. Signo y Pensamiento, 28(54), 265-275. Retrieved from http://revistas.javeriana.edu.co/index. php/signoypensamiento/article/view/4537

Boczkowski, P. J. \& de Santos, M. (2007). When More Media Equals Less News: Patterns of Content Homogenization in Argentina's Leading Print and Online Newspapers. Political Communication, 24(2), 167-180. https://doi.org/10.1080/10584600701313025

Bogart, L. (1989). Press and Public: Who Reads What, When, Where, and why in American Newspapers. Hillsdale, Michigan: Psychology Press.

Bourdieu, P. (2008). Cuestiones de sociología [Sociology issues]. Madrid: AKAL.

Cárdenas, G. (2014). Cambios de los perfiles de periodistas, medios y fuentes, producto de la fluctuación de la credibilidad de medios en el Ecuador 2009-2011 [Changes in the profiles of journalists, media and sources, product of the fluctuation of media credibility in Ecuador 2009-2011]. ComHumanitas: Revista Cientifica de Comunicación, 4(1), 109-139. Retrieved from https://goo.gl/YW5Zif

Carvajal, A. M. (2016, January 1). Supercom emitió 342 sanciones en dos años [Supercom issued 342 penalties in two years]. elcomercio.com. Retrieved from http://bit.ly/2hO5nnM

Casero-Ripollés, A. (2008). Modelos de relación entre periodistas y políticos: La perspectiva de la negociación constante [Models of relationship between journalists and politicians: The perspective of the constant negotiation]. Estudios sobre el mensaje periodistico, 14, 111-128. Retrieved from http://revistas.ucm.es/index.php/ESMP/article/view/ESMP0808110111A

Cerbino, M. \& Ramos, I. (2009). La comunicación de masas en tiempos de la revolución ciudadana: Apuntes para la democratización del espacio mediático en Ecuador [Mass communication in times of the Citizen Revolution: Notes for the democratization of the media space in Ecuador]. Comunicación: espectro América, 145, 34-39. Retrieved from https://goo.gl/HcvbNv 
Checa-Godoy, A. (2011). La batalla política y legal en Ecuador ante la creación de un sector estatal de medios informativos [The political and legal battle in Ecuador before the creation of a state-owned media sector]. Anuario Americanista Europeo, 9, 39-54. Retrieved from https://goo.gl/6zCSQ3

Dávila-Zabala, N. (2012). La crisis económica mundial: una mirada al discurso de opinión editorial en cuatro diarios ecuatorianos (2009-2010) [The global economic crisis: a look at the editorial opinion speech in four Ecuadorian newspapers (2009-2010)]. ComHumanitas: Revista Científica de Comunicación, 3(1), 73-98. Retrieved from https://goo.gl/88yVUK

De Pablos-Coello, J. M. \& Mateos-Martín, C. (2004). Estrategias informativas para acceder a un periodismo de calidad, en prensa y TV. Patologías y tabla de «medicación» para recuperar la calidad en la prensa [Information strategies to access quality journalism, in the press and TV. Pathologies and table of "medication" to recover the quality in the press]. Ambitos: revista andaluza de comunicación, (11-12), 341365. Retrieved from https://www.ull.es/publicaciones/latina/ambitos/11-12/archivos11_12/coello.pdf

Foro de Periodismo Argentino. (2008). Estándares profesionales e indicadores de calidad periodística [Professional standards and journalistic quality indicators]. Buenos Aires: Universidad de Palermo. Retrieved from http://www.palermo.edu/cienciassociales/publicaciones/pdf/FOPEA/pdf\%20para\%20 web/1Periodismo00.pdf

Gaibor-Aspiazu, M. (2013). Discurso de opinión sobre la crisis económica mundial: análisis de 5 diarios ecuatorianos [Speech on the world economic crisis: analysis of 5 Ecuadorian newspapers]. ComHumanitas: Revista Científica de Comunicación, 4(1), 175-184. Retrieved from https://goo.gl/kwsn6x

Gómez-Mompart, J. L. \& Palau-Sampio, D. (2013). El reto de la excelencia. Indicadores para medir la calidad periodística [The challenge of excellence. Indicators for measuring journalistic quality]. In J. L. Gómez Mompart, J.F. Gutiérrez-Lozano \& D. Palau-Sampaio (Eds.), La calidad periodística: teorías, investigaciones y sugerencias profesionales (Vol. 26) [Journalistic quality: theories, research and professional suggestions (Vol.26)] (pp. 17-48). Barcelona: Servei de Publicacions de la Universitat Autònoma de Barcelona.

Gutiérrez, F., Odriozola, J., Aguirre, C., Bernal, J. D., Ferreira, J., Laurencio, L., ... Aguirre, P. (2015). Periodismo condicionado. Autodiagnóstico sobre cómo cumplen su función los periodistas de Chile, Argentina, Paraguay, Ecuador, Colombia y México en la era de la transparencia [Compromised Journalism: Self-diagnosis of how Journalists perform their Role in Chile, Argentina, Paraguay, Ecuador, Colombia and Mexico in the Age of Transparency]. In Medios y periodistas en la era del Gobierno Abierto y la Transparencia [Media and Journalism in the Age of Open Government and Transparency] (pp. 159-181). Madrid: Universidad Complutense de Madrid. Retrieved from https://goo.gl/tHWkos

Gutiérrez-Atala, F., Domínguez-Panamá, J., Odriozola-Chené, J., \& Ferreira-Jiménez, J. (2017). Limitantes formativas en la praxis profesional: estudio de la situación de periodistas en Chile, México, Ecuador y Colombia [Limiting regulations in professional practice: the study of Journalist's situation in Chile, México, Ecuador and Colombia].Comuni@cción: Revista de Investigación en Comunicación y Desarrollo, 8(1), 37-47. Retrieved from https://goo.gl/P35y7d

Gutiérrez-Atala, F., Ferreira-Jiménez, J., \& Pajoni, H. (2015). Estudio sobre los efectos de la presión política y ciudadana en las rutinas profesionales de periodistas de tres ciudades latinoamericanas [Research on the effects of political and public pressure on the professional routines of journalists in three latin-american cities]. Comuni@cción - Revista de Investigación en Comunicación y Desarrollo, 6(2), 39-45. Retrieved from https://goo.gl/DK7k2V

Gutiérrez-Atala, F., Odriozola-Chéné, J., \& Domínguez-Panamá, J. J. (2017). La satisfacción de los periodistas de Ecuador, Chile y México frente a la formación universitaria y sus implicancias en el ejercicio profesional [Ecuador's, Chile's and Mexicós journalists' satisfaction in relation to university education and its implications in professional practice]. Revista de Comunicación, 16, 76-96. Retrieved from https://goo.gl/S2vYNb 
Gutiérrez-Atala, F., Odriozola-Chéné, J., Ferreira, J., Anaya-Ávila, P., \& Pajoni, H. (2016). El peso de la presión social y política: estudio de las limitaciones que condicionan el desempeño de los periodistas en cinco países latinoamericanos [The Weight of Ideological and Social Pressure: A Research on the Issues that Condition the Performance of Journalists in Five Latin American Countries]. Anuario electrónico de estudios en Comunicación Social «Disertaciones», 9(1), 84-102. https://doi.org/10.12804/disertaciones.09.01.2016.05

Igartua, J. J. \& Humanes, M. L. (2004). Teoría e investigación en comunicación social [Theory and research in social communication]. Madrid: Síntesis.

Lacy, S. \& Fico, F. (1991). The link between newspaper content quality and circulation. Newspaper Research Journal, 12(2), 46-57. https://doi.org/10.1177/073953299101200206

Magdaleno-Alegría, A. (2016). La Ley Orgánica de Comunicación de Ecuador: ¿Un avance en el ejercicio efectivo de las libertades expresión e información y en la participación ciudadana? [The Organic Law of Communication of Ecuador, is it a real move forward in the effective exercise?]. Revista de Derecho Politico, (95), 291-326. https://doi.org/10.5944/rdp.95.2016.16239

Martínez-Albertos, J. L. (2004). Aproximación a la teoría de géneros periodísticos [Approximation to the theory of journalistic genres]. In J. Canavella \& J. F. Serrano (Eds.), Redacción para periodistas. Informar e interpretar [Writing for journalists. To inform and interpret] (pp. 51-75). Barcelona: Ariel.

McInerney, C. R. \& Bird, N. J. (2005). Assessing Website quality in context: retrieving information about genetically modified food on the Web. Information Research, 10(2). Retrieved from http://goo.gl/gTj0uI

McQuail, D. (1992). Media Performance: Mass Communication and the Public Interest. Thousand Oaks, CA: Sage.

Odriozola-Chéné, J., Aguirre-Mayorga, C., \& Roa-Chejín, M. S. (2016). Los condicionantes en el desarrollo de una buena praxis periodística en Ecuador: estudio de los factores de influencia según los profesionales ecuatorianos [Determinants in the development of a good journalistic praxis in Ecuador: study of the influence factors according to ecuadorian professionals]. ComHumanitas: Revista Cientifica de Comunicación, 7(1), 89-109. Retrieved from https://goo.gl/8R6R32

Odriozola-Chéné, J., Bernal-Suárez, J. D., \& Aguirre-Mayorga, C. (2016). Influencia de la formación académica en la concepción de la profesión periodística en Ecuador [Influence of academic training in the conception of journalism as a profession in Ecuador]. Chasqui. Revista Latinoamericana de Comunicación, (133), 357-372. https://doi.org/10.16921/chasqui.v0i133.2904

Odriozola-Chené, J., Gutiérrez-Atala, F., Ferreira-Jiménez, J., \& Domínguez-Panamá, J. J. (2017). Chile, Colombia, Ecuador y México: La praxis periodística. Situación actual y principales limitantes [Chile, Colombia, Ecuador and Mexico: The journalistic praxis. Current situation and main constraints]. In A. Amado \& M. Oller-Alonso (Eds.), El periodismo por los periodistas. Perfiles profesionales en las democracias de América Latina [Journalism by journalists. Professional profiles in the democracies of Latin America] (pp. 143-161). Montevideo: Konrad Adenauer-Stiftung. Retrieved from https://goo.gl/Ewh74T

Odriozola-Chéné, J. \& Llorca-Abad, G. (2014). The Homogeneity Process in the Online Media Agenda. A Comparative Analysis of Spanish and Foreign Online Media. Comunicación y Sociedad, 27(3), 19-41. Retrieved from https://goo.gl/vYN2JW

Oller, M. (2012). La percepción de los factores de influencia por los periodistas dentro de la cultura periodística de España [The perception of the influence factors by journalists within the journalistic culture of Spain]. Revista Comunicação Midiática, 7(3), 51-69. Retrieved from https://goo.gl/P4hkRg

Oller, M. \& Chavero, P. (2015). La percepción de los factores de influencia de los periodistas dentro de la cultura periodística de Ecuador [The Perception of the Influence Factors of Journalists in the Journalistic Culture of Ecuador]. Disertaciones-Anuario Electrónico de Estudios en Comunicación Social, 8(1), 81-104. https://doi.org/10.12804/disertaciones.01.2015.04

Oller, M., Chavero, P., \& Pullas, T. (2015). El grado de confianza de los periodistas en las instituciones $\mathrm{y}$ las organizaciones de Ecuador [The degree of confidence of journalists in institutions and organizations of Ecuador]. Ambitos: Revista internacional de comunicación, (28), 81-90. Retrieved from https://goo.gl/3UkV2W 
Pellegrini, S., Puente, S., Porath, W., Mujica, C., \& Grassau, D. (2011). Valor Agregado Periodístico: la apuesta por la calidad de las noticias [Added Value Journalism: the commitment to the quality of news]. Santiago de Chile: Ediciones Universidad Católica.

Punín-Larrea, M. I. (2011). Rafael Correa y la prensa ecuatoriana. Una relación de intrigas y odios [Rafael Correa and the Ecuadorian press. A relationship of intrigues and hatreds]. Razón y palabra, 16(75). Retrieved from https://goo.gl/YrgwuX

Ramírez de la Piscina, T., González, M., Aiestarán, A., Zabalondo, B., \& Aguirre, A. (2014). Periodismo de calidad en tiempos de crisis: Un análisis de la evolución de la prensa europea de referencia (2001-2012) [Quality journalism in times of crisis: An analysis of the evolution of the European reference press (20012012)]. Revista Latina de Comunicación Social, (69), 248-274. https://doi.org/10.4185/RLCS-2014-1011

Red de Periodismo de Calidad. (2006). Propuesta de indicadores para un periodismo de calidad en México [Proposed indicators for quality journalism in Mexico]. Mexico: Universidad Iberoamericana.

Reese, S. (1999). Hacia una comprensión del periodista global. El modelo de investigación de "jerarquía de influencias" [Understanding the Global Journalist: A Hierarchy of Influences Approach]. Comunicación y Sociedad, 90(2), 47-68. Retrieved from https://goo.gl/kyf7Vj

Rodrigo-Mendizábal, I. (2010). Crisis económica y financiera mundial y opinión periodística editorial [Global economic and financial crisis and editorial journalism]. ComHumanitas: Revista Científica de Comunicación, 1(1), 123-154. Retrieved from https://goo.gl/tGrZV3

Rodrigo-Mendizábal, I. (2012). Calidad informativa: credibilidad de medios y periodistas en el Ecuador [Information quality: credibility of media and journalists in Ecuador]. ComHumanitas: Revista Científica de Comunicación, 3(1), 53-69. Retrieved from https://goo.gl/r43PNJ

Rodrigo-Mendizábal, I. (2014a). La credibilidad de medios y periodistas en Ecuador en 2013 y su relación con lo político [The credibility of media and journalists in Ecuador in 2013 and its relationship with the political arena]. ComHumanitas: Revista Científica de Comunicación, 5(1), 49-61. Retrieved from https://goo.gl/D2pCCs

Rodrigo-Mendizábal, I. (2014b). La presencia de los medios en la actual democracia: tendencias de la credibilidad en Ecuador [The presence of media in the current democracy: credibility trends in Ecuador]. Chasqui. Revista Latinoamericana de Comunicación, (127), 26-36. Retrieved from http://chasqui.ciespal.org/index.php/chasqui/article/view/2291

Shapiro, I. (2010). What's a Good Story? Recognizing Quality in Jorunalist's Work. In P. Benedetti, K. Kierans, \& T. Currie (Eds.), The New Journalist: Roles, Skills and Critical Thinking (pp. 99-112). Toronto: Edmond Montgomery.

Shoemaker, P. J. \& Reese, S. D. (2014). Mediating the Message in the 21st Century: A Media Sociology Perspective. New York: Routledge.

Teramo, M. T. (2006). Calidad de la información periodística en Argentina. Estudio de diarios y noticieros [Quality of journalistic information in Argentina. Study of newspapers and newsreels]. Palabra Clave, 9(1), 57-84. Retrieved from https://goo.gl/YrCe8U

Vásconez-Dávalos, I. (2010). La credibilidad de los medios de comunicación en el Ecuador: reflejo de un periodismo de calidad [The credibility of the media in Ecuador: a reflection of quality journalism]. ComHumanitas: Revista Científica de Comunicación, 1(1), 173-182. Retrieved from https://goo.gl/RdTjaq

Vieytes, R. (2004). Metodología de la investigación en organizaciones, mercado y sociedad: epistemología y técnicas [Research methodology in organizations, market and society: epistemology and techniques]. Buenos Aires: Editorial de las Ciencias.

Villamarín-Carrascal, J. (2013). Estándares de calidad de la información y democracia de calidad [Quality standards of information and quality democracy]. Chasqui. Revista Latinoamericana de Comunicación, (122), 23-30. Retrieved from http://chasqui.ciespal.org/index.php/chasqui/article/view/68

Wimmer, R. D. \& Dominick, J. R. (1996). La investigación científica de los medios de comunicación: una introducción a sus métodos [Mass Media Research: An Introduction]. Barcelona: Editorial Bosch. 


\section{SOBRE LOS AUTORES}

Javier Odriozola-Chéné, Doctor en Periodismo por la Universidad del País Vasco. Director de la Maestría de Investigación en Comunicación Digital y profesor de la Facultad de Comunicación de la Universidad de Los Hemisferios (Quito, Ecuador). Ha participado en proyectos centrados en: la configuración de las agendas mediáticas, las influencias para el desarrollo de la profesión periodística, el periodismo digital, periodismo ambiental y consumo de internet.

Iván Rodrigo-Mendizábal, Candidato a Doctor en Literatura Latinoamericana por la Universidad Andina Simón Bolívar [Ecuador]. Magíster en Estudios de la Cultura por la Universidad Andina Simón Bolívar [Ecuador]. Director de Posgrados y profesor de la Facultad de Comunicación de la Universidad de Los Hemisferios (Quito, Ecuador). Director de la revista iberoamericana de comunicología, Razón y Palabra. Presidente de la Sociedad Ecuatoriana de Investigadores de la Comunicación (SEICOM). Autor de diversos artículos científicos y libros. 